\title{
Black tea, green tea and risk of breast cancer: an update
}

Yili Wu, Dongfeng Zhang ${ }^{*}$ and Shan Kang

\begin{abstract}
Previous meta-analysis indicated conflicting results in case-control versus cohort studies on the association of green tea with breast cancer risk, and conflicting results were also found in case-control versus cohort studies in another meta-analysis on the association of black tea with breast cancer risk. Many studies were published after the previous meta-analysis. Besides, the dose-response relationship of tea consumption with breast cancer risk is unclear. Thus the association of tea consumption with breast cancer risk was assessed incorporating new publications. Summary relative risk (RR) for highest versus lowest level of tea consumption was calculated based on fixed or random effect models. Dose-response relationship was assessed by restricted cubic spline model and multivariate random-effect meta-regression. The combined results from 9 studies suggested no significant association between green tea consumption and breast cancer risk ( $R R=0.82,95 \% \mathrm{Cl}=0.64-1.04$ ). No significant association was found among cohort studies and case-control studies after sensitivity analysis, respectively. A linear but not significant dose-response association was found between green tea consumption and breast cancer risk. The combined results from 25 studies demonstrated no significant association between black tea consumption and breast cancer risk ( $R R=0.98,95 \% \mathrm{Cl}=0.93-1.03)$, and no significant association was found in subgroup analysis. A linear but not significant dose-response association was found between black tea consumption and breast cancer risk. Based on the current evidence, black tea and green tea might not contribute significantly to breast cancer risk, respectively.
\end{abstract}

Keywords: Black tea, Green tea, Breast cancer, Dose-response analysis

\section{To the editor,}

The most recent meta-analysis by Ogunleye et al. (Ogunleye et al. 2010) included 7 (2 cohort and 5 casecontrol) studies of green tea and breast cancer that were published as of December 2008. An inverse association between green tea and breast cancer risk was reported from case-control studies [compared to the lowest quantile, the relative risk (RR) for the highest quantile of green tea is $0.81,95 \% \mathrm{CI}=0.75-0.88$, while no association was observed from cohort studies (compared to the lowest quantile, the RR for the highest quantile of green tea is $0.85,95 \% \mathrm{CI}=0.65-1.22$ ), and the authors concluded that the association between green tea consumption and breast cancer risk remains unclear. Meanwhile, Zhou et al. (Zhou et al. 2011) suggested that a dose-response analysis

\footnotetext{
*Correspondence: zhangdf1962@yahoo.com.cn

Department of Epidemiology and Health Statistics, The Medical College of Qingdao University, Dongzhou Road, No.38, Shandong, Qingdao 266021, P. R. China
}

should be performed to assess the association between green tea and breast cancer risk. In another meta-analysis on black tea and breast cancer risk, Sun et al. (Sun et al. 2006) included 13 (5 cohort and 8 case-control) studies that were published as of August 2004. A moderate positive association between black tea consumption and risk of breast cancer was observed in cohort studies (compared to the lowest quantile, the RR for the highest quantile of black tea is $1.15,95 \% \mathrm{CI}=1.02-1.31$ ) whereas a minor inverse association was observed from the casecontrol studies (compared to the lowest quantile, the RR for the highest quantile of black tea is $0.91,95 \% \mathrm{CI}=0.84$ 0.98). Following the meta-analyses by Ogunleye et al. (Ogunleye et al. 2010), results were published from 2 prospective cohort studies (Iwasaki et al. 2010; Dai et al. 2010) on the association of green tea with risk of breast cancer. And since the meta-analysis by Sun et al. (Sun et al. 2006), results were published from 9 prospective cohort studies (Harris et al. 2012; Fagherazzi et al. 2011;

\section{Springer}




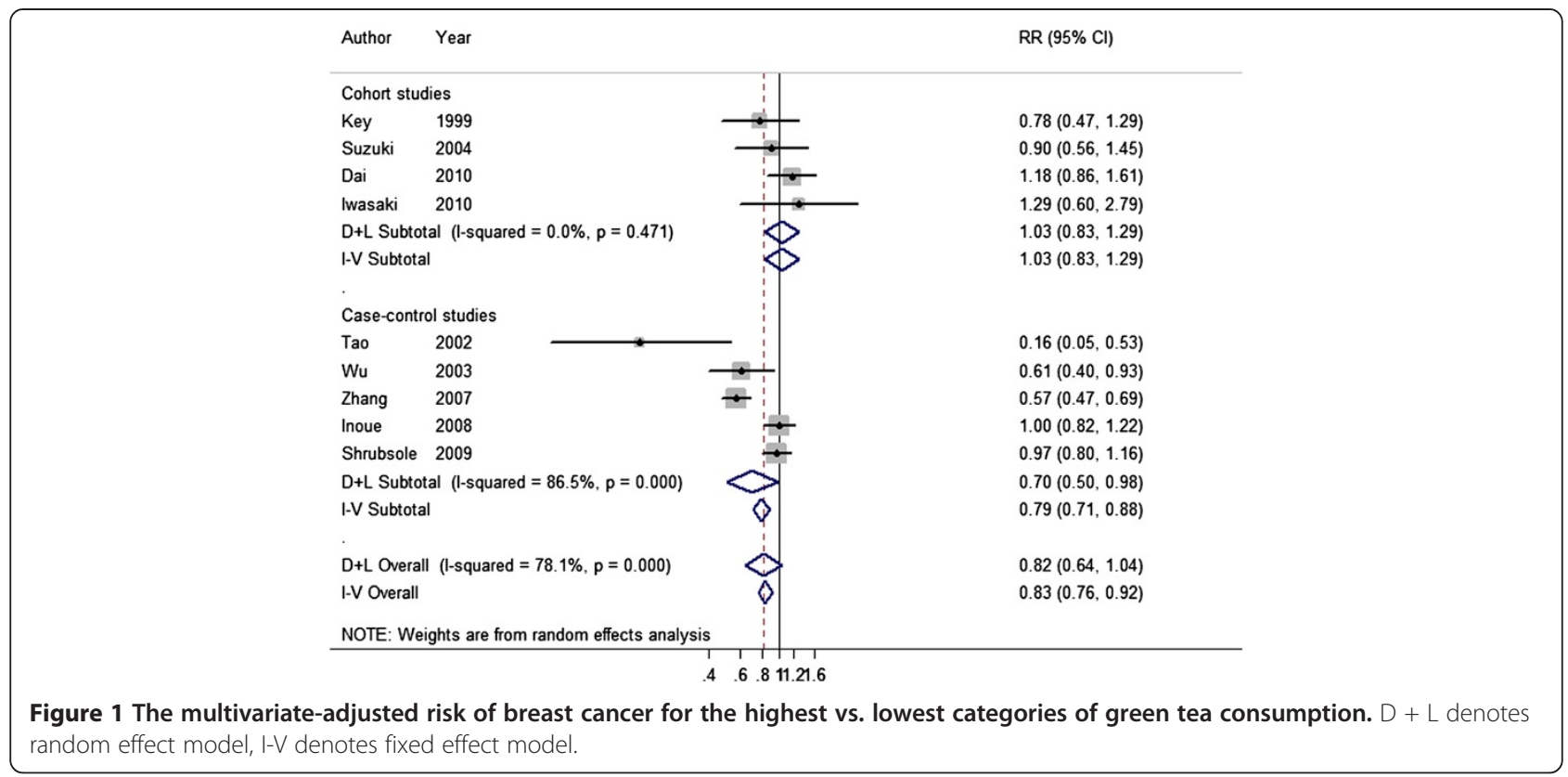

Boggs et al. 2010; Bhoo Pathy et al. 2010; Larsson et al. 2009; Ishitani et al. 2008; Ganmaa et al. 2008; Hirvonen et al. 2006; Adebamowo et al. 2005) and 3 case-control studies (Yuan et al. 2005; Kumar et al. 2009; Baker et al. 2006) on the association of black tea with breast cancer risk. Besides, we also would like to draw attention to the dose-response analysis, because categories of tea consumption differed between studies, which might complicate the interpretation of the pooled results across study populations with different categories. In this respect, a dose-response meta-analysis with restricted cubic spline functions provides a solution to the problem (Desquilbet \& Mariotti 2010), from which a summary risk estimate can be derived for a standardized increase and specific exposure values for tea consumption.

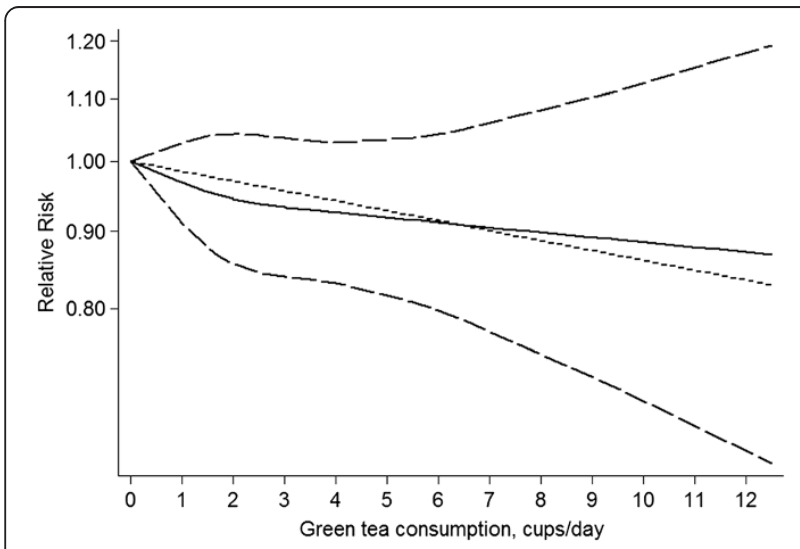

Figure 2 The dose-response analysis between green tea consumption and breast cancer risk. The solid line and the long dash line represent the estimated relative risk and its 95\% confidence interval. Short dash line represents the linear relationship.
We performed a literature search to October 2012 using the databases of Pubmed, ISI Web of Knowledge, China Biology Medical literature database and Google Scholar with the key words tea consumption combined with breast cancer. Furthermore, the reference lists of retrieved articles were scrutinized to identify additional relevant studies. If data were duplicated in more than 1 study, we included the study with the largest number of cases. RR estimates with corresponding 95\% CI for the highest vs. lowest categories of tea consumption were extracted. For dose-response analysis, the number of cases and participants (person-years), and RR (95\% CI) for each category of tea consumption were also extracted. The median or mean level of tea consumption for each category was assigned to corresponding RR for every study. If the upper boundary of the highest category was not provided, we assumed that the boundary had the same amplitude as the adjacent category. We extracted the $R R$ that reflected the greatest degree of control for potential confounders.

Pooled measure was calculated as the inverse variance-weighted mean of the logarithm of RR with 95\% CI to assess the strength of association between tea consumption and breast cancer risk. The $I^{2}$ of Higgins and Thompson was used to assess heterogeneity $\left(I^{2}\right.$ values of $0,25 \%, 50 \%$, and $75 \%$ represents no, low, moderate, and high heterogeneity (Higgins et al. 2003), respectively). The fixed effect model was used as the pooling method if moderate or lower heterogeneity $\left(I^{2}<\right.$ $50 \%)$ was found, otherwise, the random effect model was adopted $\left(I^{2} \geq 50 \%\right)$. Besides, combining studies regardless of the between-study heterogeneity had been widely criticized (Lau et al. 1998), and hierarchical systems for 


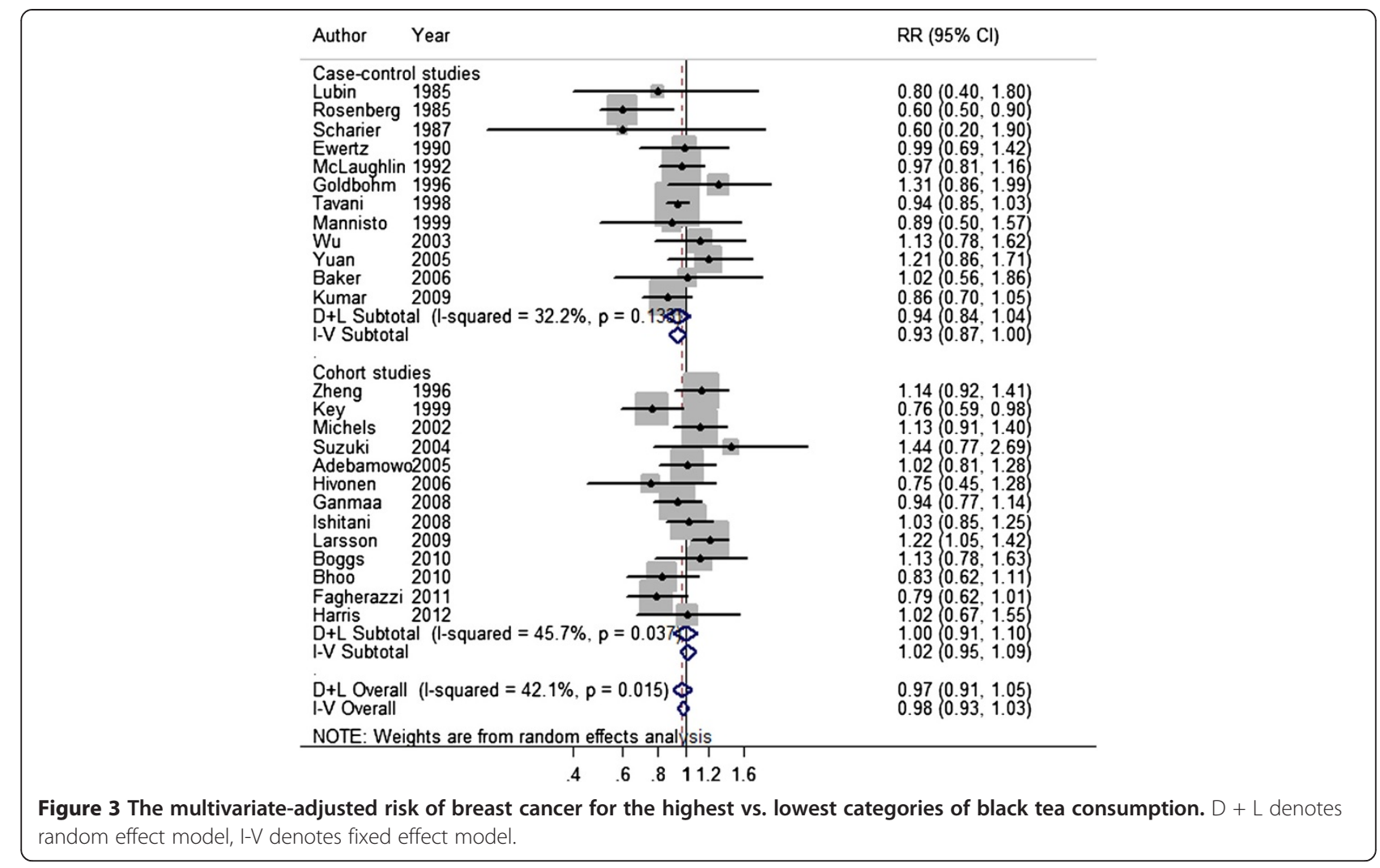

grading evidence stated that the results of studies must be consistent or homogeneous to obtain the highest grading (Harbour \& Miller 2001). Thus, sensitivity analysis was also carried out using the method by Patsopoulos et al. (Patsopoulos et al. 2008) with $I^{2}>$ $50 \%$ as the criteria to reduce between-study heterogeneity. Publication bias was detected using Egger's linear regression test (Egger et al. 1997).

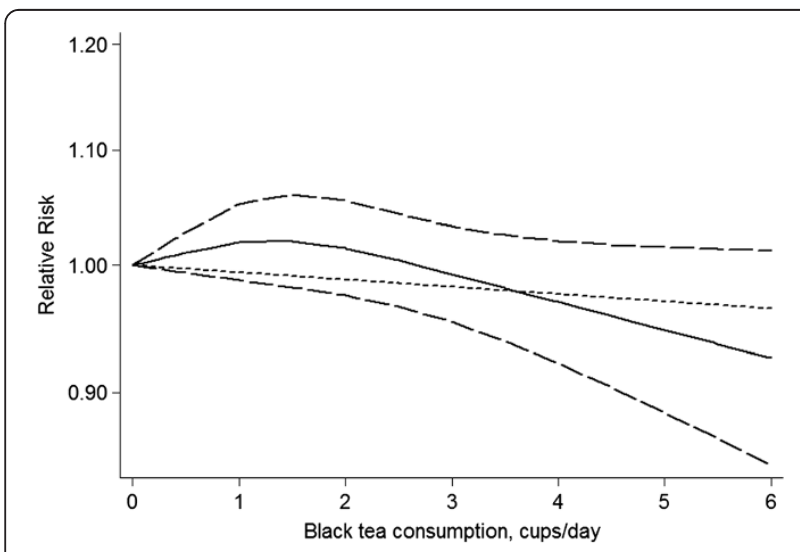

Figure 4 The dose-response analysis between black tea consumption and breast cancer risk. The solid line and the long dash line represent the estimated relative risk and its 95\% confidence interval. Short dash line represents the linear relationship.
A two-stage random-effects dose-response metaanalysis (Orsini et al. 2012) was performed to compute the trend from the correlated log RR estimates across levels of tea consumption taking into account the between-study heterogeneity. Briefly, a restricted cubic spline model, with 3 knots at the 25th, 50th and 75th percentiles (Harrell et al. 1988) of the levels of tea consumption was estimated using generalized least square regression taking into account the correlation within each set of published RRs (Orsini \& Bellocco 2006). Then multivariate random-effects meta-analysis was used to combine the study-specific estimates using restricted maximum likelihood method (Jackson et al. 2010). A $P$ value for nonlinearity was calculated by testing the null hypothesis that the coefficient of the second spline is equal to 0 . If tea consumption was indicated by gram of tea leaves or tea beverage, we rescaled tea consumption to the number of cups per day assuming $2.5 \mathrm{~g}$ tea leaves or $150 \mathrm{~g}$ tea beverage as approximately equivalent to one cup (Tang et al. 2009). All statistical analyses were performed with Stata software, version 12 (Stata Corp, College Station, Texas). P $<.05$ was considered statistically significant.

For green tea, data from 9 studies (Iwasaki et al. 2010; Dai et al. 2010; Shrubsole et al. 2009; Inoue et al. 2008; Zhang et al. 2007; Suzuki et al. 2004; Wu et al. 2003; Key et al. 1999; Tao et al. 2002) were used. Compared to 
the lowest quantile, the RR of breast cancer for the highest quantile of green tea was 0.82 (0.64-1.04), and high between-study heterogeneity was found $\left(I^{2}=78.1 \%\right)$ (Figure 1). After sensitivity analysis with $I^{2}>50 \%$ as the criteria, the association was still not significant $(R R=0.96$, $95 \% \mathrm{CI}=0.86-1.08)$. No significant association was found among cohort studies $(\mathrm{RR}=1.03,95 \% \mathrm{CI}=0.83-1.29$, $\left.I^{2}=0.00 \%\right)$. A marginally significant association was found among case-control studies ( $\mathrm{RR}=0.70,95 \% \mathrm{CI}=0.50-0.98$, $\left.I^{2}=86.5 \%\right)$, however, the association was not significant after sensitivity analysis $(\mathrm{RR}=0.98,95 \% \mathrm{CI}=0.86-1.13$, $I^{2}=0.00 \%$ ). Data from 7 studies (Iwasaki et al. 2010; Dai et al. 2010; Shrubsole et al. 2009; Zhang et al. 2007; Suzuki et al. 2004; Wu et al. 2003; Key et al. 1999) were used for dose-response analysis. A linear $(P=0.55)$ but not significant dose-response association was found between green tea consumption and breast cancer risk (Figure 2), and the risk of breast cancer decreased by $3 \%(\mathrm{RR}=0.97,95 \% \mathrm{CI}=0.90-1.04, P=0.39)$ for every 2 cups/day increment in green tea consumption. The RR $(95 \% \mathrm{CI})$ of breast cancer was 0.97 (0.91-1.03), 0.94 (0.86-1.04), 0.93 (0.84-1.04), 0.93 (0.83-1.03), 0.92 (0.81$1.04)$ and 0.91 (0.79-1.04) for $1,2,3,4,5$ and 6 cups/day of green tea consumption. No publication bias was detected $(P=0.68)$.

For black tea, data from 25 studies (Harris et al. 2012; Fagherazzi et al. 2011; Boggs et al. 2010; Bhoo Pathy et al. 2010; Larsson et al. 2009; Ishitani et al. 2008; Ganmaa et al. 2008; Hirvonen et al. 2006; Adebamowo et al. 2005; Yuan et al. 2005; Kumar et al. 2009; Baker et al. 2006; Suzuki et al. 2004; Wu et al. 2003; Key et al. 1999; Michels et al. 2002; Zheng et al. 1996; Goldbohm et al. 1996; Mannisto et al. 1999; McLaughlin et al. 1992; Ewertz \& Gill 1990; Schairer et al. 1987; Lubin et al. 1985; Tavani et al. 1998; Rosenberg et al. 1985) were used. Compared to the lowest quantile, the RR of breast cancer for the highest quantile of black tea was 0.98, $95 \% \mathrm{CI}=0.93-1.03, I^{2}=42.1 \%$ ) (Figure 3 ). The association was also not significant in subgroups by study design categorized as cohort studies $(\mathrm{RR}=1.02,95 \% \mathrm{CI}=0.95$ $\left.1.09, I^{2}=45.7 \%\right)$ and case-control studies $(\mathrm{RR}=0.94$, $\left.0.87-1.00, I^{2}=32.2 \%\right)$, menopausal status categorized as premenopausal status $(\mathrm{RR}=0.92,95 \% \mathrm{CI}=0.77-1.08$, $\left.I^{2}=15.6 \%\right)$ and postmenopausal status $(\mathrm{RR}=1.07,95 \%$ $\mathrm{CI}=0.96-1.21, I^{2}=0.00 \%$ ), estrogen receptor (ER) and progesterone receptor $(\mathrm{PR})$ status (negative: -; positive: + ) categorized as $\mathrm{ER}+/ \mathrm{PR}+(\mathrm{RR}=1.03,95 \% \mathrm{CI}=0.80-1.34$, $\left.I^{2}=63.9 \%\right)$ and $\mathrm{ER}-/ \mathrm{PR}-(\mathrm{RR}=0.84,95 \% \mathrm{CI}=0.68-1.03$, $I^{2}=0.00 \%$ ), as well as body mass index (BMI) categorized as $\mathrm{BMI}<25 \mathrm{~kg} / \mathrm{m}^{2}(\mathrm{RR}=0.98,95 \% \mathrm{CI}=0.81-1.18$, $\left.I^{2}=51.2 \%\right)$ and $\mathrm{BMI}>25 \mathrm{~kg} / \mathrm{m}^{2}(\mathrm{RR}=1.02,95 \% \mathrm{CI}=0.84$ $\left.1.24, I^{2}=0.00 \%\right)$. After sensitivity analysis with $I^{2}>$ $50 \%$ as the criteria, the association was still not significant for $E R+/ P R+$ breast cancer $(R R=0.93,95 \%$
$\mathrm{CI}=0.82-1.05, I^{2}=0.00 \%$ ), and no significant association was found among subjects with $\mathrm{BMI}<25 \mathrm{~kg} / \mathrm{m}^{2}$ ( $\mathrm{RR}=1.07$, $\left.95 \% \mathrm{CI}=0.86-1.33, I^{2}=0.00 \%\right)$. Data from 19 studies (Harris et al. 2012; Fagherazzi et al. 2011; Boggs et al. 2010; Bhoo Pathy et al. 2010; Larsson et al. 2009; Ganmaa et al. 2008; Hirvonen et al. 2006; Adebamowo et al. 2005; Kumar et al. 2009; Baker et al. 2006; Wu et al. 2003; Key et al. 1999; Michels et al. 2002; Zheng et al. 1996; Goldbohm et al. 1996; Ewertz \& Gill 1990; Schairer et al. 1987; Lubin et al. 1985; Rosenberg et al. $1985)$ were used for dose-response analysis. A linear $(P=0.09)$ but not significant dose-response association was found between black tea consumption and breast cancer risk (Figure 4), and the risk of breast cancer decreased by $1 \%(\mathrm{RR}=0.99,95 \% \mathrm{CI}=0.96-1.03, P=0.68)$ for every 2 cups/day increment in black tea consumption. The RR (95\% CI) of breast cancer was $1.02(0.99-$ 1.05), 1.01 (0.98-1.05), 0.99 (0.95-1.03), 0.97 (0.92-1.02), $0.95(0.89-1.01)$ and $0.93(0.85-1.01)$ for $1,2,3,4,5$ and 6 cups/day of black tea consumption. No publication bias was detected $(P=0.79)$.

Overall, this analysis suggested that black tea and green tea might not contribute significantly to breast cancer risk based on the current evidence, respectively. However, further researches deserve to address the possible interaction effects between tea and other dietary/ genetic cofactors.

\section{Competing interest}

The authors declare that they have no competing interest.

\section{Authors' contributions}

WYL and KS carried out the collection, assembly, analysis and interpretation of data. WYL and ZDF participated in the drafting and revision of the

manuscript. All authors read and approved the final manuscript.

Received: 16 April 2013 Accepted: 29 April 2013

Published: 24 May 2013

\section{References}

Adebamowo CA, Cho E, Sampson L et al (2005) Dietary flavonols and flavonolrich foods intake and the risk of breast cancer. Int J Cancer 114:628-633

Baker JA, Beehler GP, Sawant AC, Jayaprakash V, McCann SE, Moysich KB (2006) Consumption of coffee, but not black tea, is associated with decreased risk of premenopausal breast cancer. J Nutr 136:166-171

Bhoo Pathy N, Peeters P, van Gils C et al (2010) Coffee and tea intake and risk of breast cancer. Breast Cancer Res Treat 121:461-467

Boggs DA, Palmer JR, Stampfer MJ, Spiegelman D, Adams-Campbell LL, Rosenberg $L$ (2010) Tea and coffee intake in relation to risk of breast cancer in the black Women's health study. Cancer Causes Control 21:1941-1948

Dai Q, Shu XO, Li H et al (2010) Is green tea drinking associated with a later onset of breast cancer? Ann Epidemiol 20:74-81

Desquilbet L, Mariotti F (2010) Dose-response analyses using restricted cubic spline functions in public health research. Stat Med 29:1037-1057

Egger M, Davey Smith G, Schneider M, Minder C (1997) Bias in meta-analysis detected by a simple, graphical test. BMJ 315:629-634

Ewertz M, Gill C (1990) Dietary factors and breast-cancer risk in Denmark. Int J Cancer 46:779-784

Fagherazzi G, Touillaud MS, Boutron-Ruault MC, Clavel-Chapelon F, Romieu I (2011) No association between coffee, tea or caffeine consumption and breast cancer risk in a prospective cohort study. Public Health Nutr 14:1315-1320

Ganmaa D, Willett WC, Li TY et al (2008) Coffee, tea, caffeine and risk of breast cancer: a 22-year follow-up. Int J Cancer 122:2071-2076 
Goldbohm RA, Hertog MG, Brants HA, van Poppel G, van den Brandt PA (1996) Consumption of black tea and cancer risk: a prospective cohort study. J Nat Cancer Inst 88:93-100

Harbour R, Miller J (2001) A new system for grading recommendations in evidence based guidelines. BMJ 323:334-336

Harrell FE Jr, Lee KL, Pollock BG (1988) Regression models in clinical studies: determining relationships between predictors and response. J Natl Cancer Inst 80:1198-1202

Harris HR, Bergkvist L, Wolk A (2012) Coffee and black tea consumption and breast cancer mortality in a cohort of Swedish women. Br J Cancer 107:874-878

Higgins JP, Thompson SG, Deeks JJ, Altman DG (2003) Measuring inconsistency in meta-analyses. BMJ 327:557-560

Hirvonen T, Mennen LI, de Bree A et al (2006) Consumption of antioxidant-rich beverages and risk for breast cancer in French women. Ann Epidemiol 16:503-508

Inoue M, Robien K, Wang R, Van Den Berg DJ, Koh WP, Yu MC (2008) Green tea intake, MTHFR/TYMS genotype and breast cancer risk: the Singapore Chinese health study. Carcinogenesis 29:1967-1972

Ishitani K, Lin J, Manson JE, Buring JE, Zhang SM (2008) Caffeine consumption and the risk of breast cancer in a large prospective cohort of women. Arch Intern Med 168:2022-2031

Iwasaki M, Inoue M, Sasazuki S et al (2010) Green tea drinking and subsequent risk of breast cancer in a population-based cohort of Japanese women. Breast Cancer Res 12:R88

Jackson D, White IR, Thompson SG (2010) Extending DerSimonian and Laird's methodology to perform multivariate random effects meta-analyses. Stat Med 29:1282-1297

Key TJ, Sharp GB, Appleby PN et al (1999) Soya foods and breast cancer risk: a prospective study in Hiroshima and Nagasaki, Japan. Br J Cancer 81:1248-1256

Kumar N, Titus-Ernstoff L, Newcomb PA, Trentham-Dietz A, Anic G, Egan KM (2009) Tea consumption and risk of breast cancer. Cancer Epidemiol Biomarkers Prev 18:341-345

Larsson SC, Bergkvist L, Wolk A (2009) Coffee and black tea consumption and risk of breast cancer by estrogen and progesterone receptor status in a Swedish cohort. Cancer Causes Control 20:2039-2044

Lau J, loannidis JP, Schmid CH (1998) Summing up evidence: one answer is not always enough. Lancet 351:123-127

Lubin F, Ron E, Wax Y, Modan B (1985) Coffee and methylxanthines and breast cancer: a case-control study. J Natl Cancer Inst 74:569-573

Mannisto S, Pietinen P, Virtanen M, Kataja V, Uusitupa M (1999) Diet and the risk of breast cancer in a case-control study: does the threat of disease have an influence on recall bias? J Clin Epidemiol 52:429-439

McLaughlin CC, Mahoney MC, Nasca PC, Metzger BB, Baptiste MS, Field NA (1992) Breast cancer and methylxanthine consumption. Cancer Causes Control 3:175-178

Michels KB, Holmberg L, Bergkvist L, Wolk A (2002) Coffee, tea, and caffeine consumption and breast cancer incidence in a cohort of Swedish women. Ann Epidemiol 12:21-26

Ogunleye AA, Xue F, Michels KB (2010) Green tea consumption and breast cancer risk or recurrence: a meta-analysis. Breast Cancer Res Treat 119:477-484

Orsini N, Bellocco RSG (2006) Generalized least squares for trend estimation of summarized dose-response data. Stata J 6:40-57

Orsini N, Li R, Wolk A, Khudyakov P, Spiegelman D (2012) Meta-analysis for linear and nonlinear dose-response relations: examples, an evaluation of approximations, and software. Am J Epidemiol 175:66-73

Patsopoulos NA, Evangelou E, loannidis JP (2008) Sensitivity of between-study heterogeneity in meta-analysis: proposed metrics and empirical evaluation. Int J Epidemiol 37:1148-1157

Rosenberg L, Miller DR, Helmrich SP et al (1985) Breast cancer and the consumption of coffee. Am J Epidemiol 122:391-399

Schairer C, Brinton LA, Hoover RN (1987) Methylxanthines and breast cancer. Int J Cancer 40:469-473

Shrubsole MJ, Lu W, Chen Z et al (2009) Drinking green tea modestly reduces breast cancer risk. J Nutr 139:310-316

Sun CL, Yuan JM, Koh WP, Yu MC (2006) Green tea, black tea and breast cancer risk: a meta-analysis of epidemiological studies. Carcinogenesis 27:1310-1315

Suzuki Y, Tsubono Y, Nakaya N, Koizumi Y, Tsuji I (2004) Green tea and the risk of breast cancer: pooled analysis of two prospective studies in Japan. $\mathrm{Br} J$ Cancer 90:1361-1363

Tang N, Wu Y, Zhou B, Wang B, Yu R (2009) Green tea, black tea consumption and risk of lung cancer: a meta-analysis. Lung Cancer 65:274-283
Tao MH, Liu DK, Gao LF, Jin F (2002) Association between green tea drinking and breast cancer risk. Tumor 22:11-15

Tavani A, Pregnolato A, La Vecchia C, Favero A, Franceschi S (1998) Coffee consumption and the risk of breast cancer. Eur J Cancer Prev 7:77-82

Wu AH, Yu MC, Tseng CC, Hankin J, Pike MC (2003) Green tea and risk of breast cancer in Asian Americans. Int J Cancer 106:574-579

Yuan JM, Koh WP, Sun CL, Lee HP, Yu MC (2005) Green tea intake, ACE gene polymorphism and breast cancer risk among Chinese women in Singapore. Carcinogenesis 26:1389-1394

Zhang M, Holman CD, Huang JP, Xie X (2007) Green tea and the prevention of breast cancer: a case-control study in Southeast China. Carcinogenesis 28:1074-1078

Zheng W, Doyle TJ, Kushi LH, Sellers TA, Hong CP, Folsom AR (1996) Tea consumption and cancer incidence in a prospective cohort study of postmenopausal women. Am J Epidemiol 144:175-182

Zhou P, Li JP, Zhang C (2011) Green tea consumption and breast cancer risk: three recent meta-analyses. Breast Cancer Res Treat 127:581-583

doi:10.1186/2193-1801-2-240

Cite this article as: Wu et al:: Black tea, green tea and risk of breast cancer: an update. SpringerPlus 2013 2:240.

\section{Submit your manuscript to a SpringerOpen ${ }^{\circ}$ journal and benefit from:}

- Convenient online submission

- Rigorous peer review

- Immediate publication on acceptance

- Open access: articles freely available online

- High visibility within the field

- Retaining the copyright to your article

Submit your next manuscript at $>$ springeropen.com 